\title{
Regulatory Mechanisms of Autophagy-Targeted Antimicrobial Therapeutics Against Mycobacterial Infection
}

\author{
Prashanta Silwal ${ }^{1,2}$, Seungwha Paik ${ }^{1,2}$, Jin Kyung Kim ${ }^{1,2}$, Tamotsu Yoshimori ${ }^{3,4}$ \\ and Eun-Kyeong Jo ${ }^{1,2 *}$
}

${ }^{1}$ Department of Microbiology, Chungnam National University School of Medicine, Daejeon, South Korea, 2 Infection Control Convergence Research Center, Chungnam National University School of Medicine, Daejeon, South Korea, ${ }^{3}$ Department of Genetics, Graduate School of Medicine, Osaka University, Osaka, Japan, ${ }^{4}$ Department of Intracellular Membrane Dynamics, Graduate School of Frontier Biosciences, Osaka University, Osaka, Japan

OPEN ACCESS

Edited by:

Selvakumar Subbian

Public Health Research Institute

(PHRI), United States

Reviewed by:

Chul-Su Yang,

Hanyang University, South Korea

Annemarie H. Meijer,

Leiden University, Netherlands

Matt Johansen,

University of Technology Sydney,

Australia

*Correspondence:

Eun-Kyeong Jo

hayoungj@cnu.ac.kr

Specialty section:

This article was submitted to

Clinical Microbiology,

a section of the journa

Frontiers in Cellular

and Infection Microbiology

Received: 25 November 2020

Accepted: 08 January 2021

Published: 22 March 2021

Citation:

Silwal P, Paik S, Kim JK, Yoshimori T and Jo E-K (2021) Regulatory

Mechanisms of Autophagy-Targeted Antimicrobial Therapeutics Against

Mycobacterial Infection.

Front. Cell. Infect. Microbiol. 11:633360.

doi: 10.3389/fcimb.2021.633360
Mycobacterium tuberculosis (Mtb) is an intracellular pathogen causing human tuberculosis, an infectious disease that still remains as a global health problem. Autophagy, a lysosomal degradative process, has emerged as a critical pathway to restrict intracellular Mtb growth through enhancement of phagosomal maturation. Indeed, several autophagy-modulating agents show promise as host-directed therapeutics for Mtb infection. In this Review, we discuss recent progress in our understanding the molecular mechanisms underlying the action of autophagy-modulating agents to overcome the immune escape strategies mediated by Mtb. The factors and pathways that govern such mechanisms include adenosine 5'-monophosphate-activated protein kinase, Akt/mammalian TOR kinase, Wnt signaling, transcription factor EB, cathelicidins, inflammation, endoplasmic reticulum stress, and autophagy-related genes. A further understanding of these mechanisms will facilitate the development of host-directed therapies against tuberculosis as well as infections with other intracellular bacteria targeted by autophagic degradation.

Keywords: autophagy, AMPK, mTOR, Mycobacterium tuberculosis, host-directed therapeutics

\section{INTRODUCTION}

Autophagy is an intracellular degradation process that maintains cell homeostasis during stress conditions (Ryter et al., 2013). Autophagy process is linked to various biological responses, including inflammation, metabolism, and innate effector pathways (Gutierrez et al., 2004; Deretic, 2008; Rabinowitz and White, 2010; Kimmey et al., 2015; Bergman et al., 2020; Chai et al., 2020; Mendes et al., 2020; Painter et al., 2020). Mycobacterium tuberculosis (Mtb) is the causal pathogen of human tuberculosis, a serious infectious disease with an increasing burden of drug resistance (Zumla et al., 2015; WHO, 2020). Autophagy functions as a cell-autonomous defensive pathway against intracellular Mtb (Gutierrez et al., 2004; Kimmey et al., 2015). After phagocytosis, a majority of Mtb resides in phagosome to escape the phagolysosomal acidification, but some of them 
access to cytosol and can be targeted by xenophagy (Watson et al., 2012; Manzanillo et al., 2013; Gomes and Dikic, 2014; Paik et al., 2019). Indeed, a variety of agents triggering autophagy/ xenophagy promote phagosomal maturation through autophagic capture of either intraphagosomal Mtb or cytosolic pathogens (Gupta et al., 2016; Kim Y. S. et al., 2019).

In this Review, we outline the mechanisms underlying the effects of autophagy-based agents to enhance host defense against Mtb infection. In particular, we discuss the mechanisms and signaling pathways (adenosine $5^{\prime}$-monophosphate [AMP]activated protein kinase [AMPK], mammalian target of rapamycin [mTOR] kinase, Wnt, transcription factor EB [TFEB], cathelicidins, inflammation, endoplasmic reticulum [ER] stress, and autophagy-related genes [ATGs]) that would make autophagy-activating agents a potential host-directed therapeutic (HDT) or alternative to current tuberculosis (TB) chemotherapeutics.

\section{OVERVIEW OF AUTOPHAGY DURING MYCOBACTERIAL INFECTION}

Autophagy is a catabolic process of damaged cellular components to ensure cell survival and homeostasis (Glick et al., 2010; Ryter et al., 2013). There are three canonical autophagy pathways-macroautophagy, microautophagy, and chaperone-mediated autophagy, which differ in how the cargo is targeted and delivered to lysosomes (Glick et al., 2010; Ryter et al., 2013). Macroautophagy (hereafter referred to as autophagy) is activated by stress signals including starvation, hypoxia, and infections, and is characterized by the formation of double-membraned autophagosomes, which fuse with a lysosome to form an autolysosome, the site of cargo degradation (Glick et al., 2010; Ryter et al., 2013).

Mtb has developed numerous strategies to avoid autophagic defense and manipulate host innate immunity (Jiao and Sun, 2019). For example, via the ESX-1 system, Mtb suppresses the late-stage autophagy in human dendritic cells to escape dendritic cell-mediated immunity (Romagnoli et al., 2012). The enhanced intracellular survival (Eis) gene of Mtb inhibits macrophage autophagy, at least partly mediated through suppression of cJun N-terminal kinase (JNK)-reactive oxygen species (ROS) signaling, in macrophages (Shin et al., 2010a). Also, Mtb lipoprotein LprE inhibits autophagy and cathelicidin expression to favor bacterial replication during infection (Padhi et al., 2019). In addition, virulent Mtb strains inhibit the recruitment of Rab7, the late endosomal/lysosomal protein, to the phagosomes, thereby escaping from phagosomal fusion with lysosomes (Chandra et al., 2015; Chandra and Kumar, 2016). However, ATGs, except ATG5, in myeloid cells do not appear to be essential in the activation of host defense in vivo (Kimmey et al., 2015). In addition, Mtb pathogens can epigenetically control host autophagy pathway through regulation of microRNAs (miRNAs) to favor mycobacterial replication in the host cells during infection (Batista et al., 2020;
Ruiz-Tagle et al., 2020; Silwal et al., 2020). The miRNAs that are associated with pathogenesis of Mtb infection include miR-33/ miR-33* (Ouimet et al., 2016), miR-889 (Chen et al., 2020), miR18a (Yuan et al., 2020), and miR-125a (Kim et al., 2015), all of which are increased by Mtb infection; whereas others such as miR-26a (Sahu et al., 2017) and miR-17-5p (Kumar et al., 2016), both of which are decreased by Mtb infection. Numerous miRNAs that are involved in the regulation of autophagy in terms of host-pathogen interaction during Mtb infection have been extensively discussed elsewhere (Kim J. K. et al., 2017; Sabir et al., 2018; Yang and Ge, 2018; Silwal et al., 2020; Sinigaglia et al., 2020) and are not the focus of this Review. Thus, it remains to be fully characterized the exact mechanisms by which Mtb evade from host autophagic defense system, although several autophagy-activating drugs/agents are able to suppress Mtb growth in vitro and in vivo (Stanley et al., 2014; Gupta et al., 2016; Paik et al., 2019).

Noncanonical autophagy includes selective autophagy processes, such as xenophagy (intracellular bacteria) (Chai et al., 2019), mitophagy (damaged mitochondria) (Lazarou et al., 2015), lipophagy (lipid droplets) (Zhao et al., 2020), and etc. The ESX-1 system of Mtb is responsible for phagosomal damage and cytoplasmic release of bacteria and its ubiquitination, recruiting autophagic adaptors such as p62 and NDP52 to activate xenophagy (Manzanillo et al., 2013; Kim Y. S. et al., 2019). During xenophagy process, the ubiquitin ligases Parkin and Smurf1 are involved in the ubiquitination of cytosolic Mtb (Manzanillo et al., 2013; Franco et al., 2017). The DNA sensor cGAS triggers xenophagy through recognition of cytosolic Mtb DNA (Watson et al., 2015). Recent study showed that ubiquitin directly binds to the Mtb surface protein Rv1468c, triggering p62-mediated xenophagy (Chai et al., 2019). Advances in the identification on Mtb effector(s) to activate or inhibit xenophagy will elucidate the precise molecular mechanisms underlying Mtb manipulation of host autophagic process.

In addition, LC3-associated phagocytosis (LAP), another form of noncanonical autophagy (Sanjuan et al., 2009), appears to be essential for host defense against mycobacterial infection (Koster et al., 2017). LAP links between pattern recognition receptor (PRRs) signaling and phagosomal maturation, and is characterized by a single-membrane phagosomal structure (Sanjuan et al., 2009; Sprenkeler et al., 2016). Unlike canonical autophagy, LAP does not require pre-initiation of the autophagy machinery complex (Sanjuan et al., 2009; Sprenkeler et al., 2016), but makes use of Rubicon and NADPH oxidase 2 (NOX2) (Martinez et al., 2015). The mycobacterial protein CpsA protects Mtb from NOX2-dependent ROS and subsequent LAP-mediated killing (Koster et al., 2017). It is warranted to clarify how Mtb and its products orchestrate LAP function to escape from host anti-mycobacterial responses. Mtb-induced regulation of xenophagy and LAP is summarized in Figure 1.

So far, numerous agents/small molecules to promote host anti-mycobacterial defense through targeting autophagy have been discussed (Palucci and Delogu, 2018; Singh and Subbian, 2018; Kim Y. S. et al., 2019; Paik et al., 2019). In this Review, we focus on recent advances of several mechanisms by which 


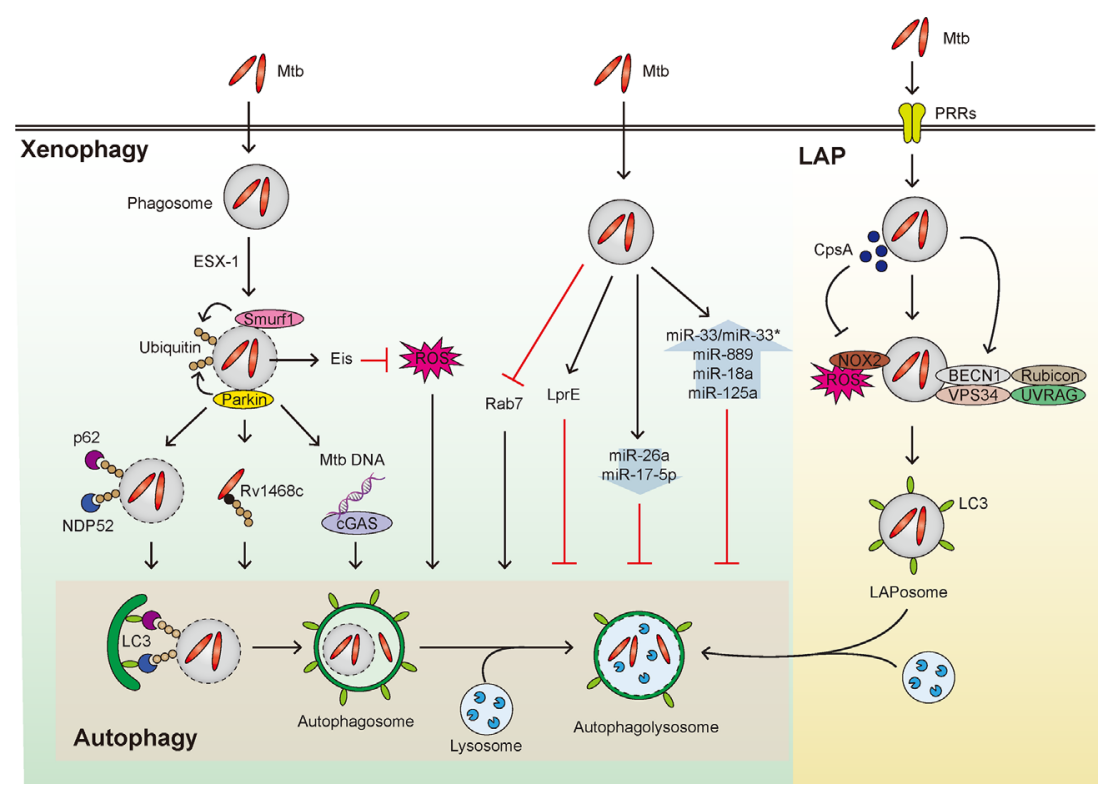

FIGURE 1 | Overview of xenophagy and LAP during Mtb infection. Xenophagy and LAP are activated in host cells during Mtb infection. (Left) Mtb that enters the host cells by phagocytosis can reside within phagosomes and resist fusion with lysosomes. The phagosome is then damaged by the ESX-1 system to induce Smurf1- and Parkin-mediated ubiquitination, thereby adaptor proteins such as p62 and NDP52 are recruited leading to formation of autophagosome. Also, Rv1468c, a surface protein of Mtb that escapes from the phagosome, induces xenophagy by binding with ubiquitin. In addition, the Mtb DNA exposed to the cytosol from the damaged phagosome is recognized by cGAS to induce xenophagy. Both the enhanced intracellular survival (Eis) gene of Mtb and putative Mtb lipoprotein LprE inhibit autophagy. Additionally, several miRNAs that inhibit xenophagy are shown in the context of mycobacterial infection. In addition, Mtb inhibits the recruitment of Rab7, thus disturbing the fusion of autophagosome and lysosome. (Right) Various PRRs recognize Mtb and invade the host cell. Rubicon complex (RubiconBECN1-VPS34-UVRAG) and NOX2-dependent ROS are important in the activation of LAP. In this process, LAPosome, a single membrane surrounded by LC3 is formed, which fuses with lysosome to eliminate Mtb. At this time, it is known that CpsA, a protein of Mtb, interferes with the LAP mechanism.

autophagy-targeting startegies enhance host defense against mycobacterial infections.

\section{AMPK AND INNATE HOST DEFENSE AGAINST MTB}

AMPK, a key metabolic regulator, plays a role in the regulation of autophagy during a variety of stress conditions. Pharmacological activation of AMPK has therapeutic potential for a variety of human diseases, including ischemia-reperfusion (I/R) injuries, cardiovascular diseases, and bone-related diseases (Ding et al., 2020; Li et al., 2020; Tong et al., 2020). In addition, the AMPK pathway is involved in the antimicrobial response to Mtb infection (Silwal et al., 2018). The AMPK activator AICAR and the mycobacterial lipoprotein LpqH are able to activate autophagy in macrophages via AMPK signaling pathway (Shin et al., 2010b; Yang et al., 2014). A recent study suggest a potential role for TNF-like weak inducer of apoptosis (TWEAK) in AMPK-mediated autophagy activation during mycobacterial infection. TWEAK levels are upregulated in human peripheral blood mononuclear cells by stimulation with heat-killed Mtb or secreted proteins of $\mathrm{Mtb}$, and in sera from TB patients at the early phase, but declined in patients with latent tuberculosis infection (LTBI) (Chen et al., 2020). TWEAK activates autophagy and phagosomal maturation in macrophages through activation of AMPK (Chen et al., 2020). Interestingly, the increased miR-889 level in LTBI suppresses autophagy through targeting TWEAK; and after TNF- $\alpha$ inhibitor therapy, TWEAK level decreases, thereby contributing to LTBI reactivation in rheumatoid arthritis patients with LTBI (Chen et al., 2020).

Mtb infection increases miR-18a expression to suppress the autophagy; and miR-18a inhibition increases AMPK phosphorylation and promotes autophagy, resulting in suppression of intracellular Mtb survival (Yuan et al., 2020). Mtb induction of $\mathrm{miR} 33 / 33^{*}$ supports intracellular bacterial replication by inhibiting the autophagic flux via repression of AMPKdependent activation of forkhead box O (FOXO) 3 and TFEB (Ouimet et al., 2016). In addition, AMPK activation by AICAR or resveratrol induces transcriptional and post-translational activation of autophagy genes via orphan nuclear receptor estrogen-related receptor (ERR)- $\alpha$ (Kim S. Y. et al., 2018). These data suggest that AMPK activation can be regulated transcriptionally or epigenetically in the context of the autophagy activation. Further studies are needed to elucidate the exact molecular pathways through which AMPK-induced autophagy activation contributes to host defense against Mtb infection.

Recent studies have highlighted the roles of metabolites in the activation of autophagy and host defense through AMPK signaling (Kim J. K. et al., 2018; Sivangala Thandi et al., 2020). A metabolite 
ornithine is implicated in Kupffer cell-specific host defense against Mtb infection. Ornithine, a product of Mtb-infected Kupffer cells, induces autophagy through AMPK, thereby restricting Mtb growth (Sivangala Thandi et al., 2020). The neurotransmitter and metabolite gamma-aminobutyric acid (GABA) triggers autophagy by activating AMPK through calcium flux, and leads to enhanced innate host defense against Mtb infection (Kim J. K. et al., 2018). Although not confirmed in human trials, these preclinical observations suggest the utility of autophagy-targeting metabolites for HDTs against TB. Autophagy-based antimicrobial responses acting through AMPK are summarized in Table $\mathbf{1 .}$

\section{THE MTOR/AKT PATHWAY AND HOST DEFENSE AGAINST MTB}

$\mathrm{mTOR}$ is a serine/threonine protein kinase consisting of mTORC1 and mTORC2 (Jhanwar-Uniyal et al., 2019), and regulates a variety of biological processes, including protein synthesis, cell proliferation, growth, autophagy, and metabolism (Gibbons et al., 2009; Kaur and Sharma, 2017; Qian et al., 2020). mTORC1 is regulated by the phosphatidylinositol 3-kinase (PI3K)/Akt pathway, constitutive activation of which suppresses autophagy process (Kaleagasioglu et al., 2020). Earlier studies showed that $\mathrm{Mtb}$ and its components can trigger the signaling pathways of PI3K/Akt and mTOR/S6K1 in macrophages (Maiti et al., 2001; Yang et al., 2006; Yang et al., 2014). Thus, it is possible that Mtbmediated mTOR/Akt signaling may play a major role for suppression of macroautophagy during infection (Yang et al., 2006; Yang et al., 2014). Rapamycin, a suppressor of mTORC1, is a classical activator of autophagy (Li et al., 2014), shows an antimicrobial effect upon intracellular Mtb replication, as reported in earlier study (Gutierrez et al., 2004). Because novel analogs of rapamycin (temsirolimus, everolimus, and deforolimus) have therapeutic potential through activation of autophagy in the context of various diseases including cancers (Yazbeck et al., 2008;

TABLE 1 | Autophagy-based antimicrobial responses acting through AMPK and Akt/mTOR pathways.

\begin{tabular}{|c|c|c|c|c|}
\hline Activator & Study model & Pathogen & Mechanism & Ref. \\
\hline \multicolumn{5}{|l|}{ AMPK } \\
\hline AICAR & $\begin{array}{l}\text { BMDMs, RAW264.7 \& } \\
\text { THP-1 cells }\end{array}$ & Mtb H37Rv & $\begin{array}{l}\text { Upregulation of autophagy-related genes expression through AMPK- } \\
\text { PPARGC1A pathway }\end{array}$ & $\begin{array}{l}\text { (Yang et al., } \\
\text { 2014) }\end{array}$ \\
\hline AICAR & BMDMs & Mtb H37Rv & $\begin{array}{l}\text { Induction of AMPK/SIRT1-mediated ESSRA to enhance the transcriptional } \\
\text { and post-transcriptional activation of autophagy genes }\end{array}$ & $\begin{array}{l}\text { (Kim S. Y. et al., } \\
\text { 2018) }\end{array}$ \\
\hline $\mathrm{LpqH}$ & $\begin{array}{l}\text { Human primary } \\
\text { monocytes }\end{array}$ & Mtb H37Rv & $\begin{array}{l}\text { Induction of TLR2/1/CD14-mediated C/EBP- } \beta \text {-dependent CYP27B1 } \\
\text { hydrolase and cathelicidin expression, } \\
\text { Activation of } \mathrm{Ca}^{2+} / \mathrm{AMPK} / \mathrm{p} 38 \text { MAPK signaling pathway }\end{array}$ & $\begin{array}{l}\text { (Shin et al., } \\
\text { 2010b) }\end{array}$ \\
\hline TWEAK & THP-1 cells & M. bovis BCG & Promotion of mycobacterial phagosomal maturation through AMPK activation & $\begin{array}{l}\text { (Chen et al., } \\
\text { 2020) }\end{array}$ \\
\hline miR-18a inhibitor & RAW264.7 cells & Mtb H37Rv & Regulation of ATM-AMPK pathway & (Yuan et al., 2020) \\
\hline $\begin{array}{l}\mathrm{miR}-33 / \mathrm{miR}-33^{*} \\
\text { inhibitor }\end{array}$ & PMs & Mtb H37Rv & Activation of AMPK-dependent FOXO3 and TFEB & $\begin{array}{l}\text { (Ouimet et al., } \\
\text { 2016) }\end{array}$ \\
\hline Ornithine & $\begin{array}{l}\text { Mouse alveolar } \\
\text { macrophages, Kupffer } \\
\text { cells }\end{array}$ & Mtb H37Rv & Reduction of ammonia and induction of AMPK & $\begin{array}{l}\text { (Sivangala Thandi } \\
\text { et al., 2020) }\end{array}$ \\
\hline GABA & BMDMs & Mtb H37Rv & $\begin{array}{l}\text { Activation of } \mathrm{GABA}_{\mathrm{A}} \mathrm{R}-\mathrm{Ca}^{2+} \text {-AMPK signaling, } \\
\text { GABARAPL1-mediated phagosomal maturation }\end{array}$ & $\begin{array}{l}\text { (Kim J. K. et al., } \\
\text { 2018) }\end{array}$ \\
\hline \multicolumn{5}{|l|}{ Akt/mTOR } \\
\hline Bazedoxifene & THP-1 cells & Mtb H37Ra & Induction of ROS production and inhibition of Akt/mTOR signaling & $\begin{array}{l}\text { (Ouyang et al., } \\
\text { 2020) }\end{array}$ \\
\hline Nilotinib & BMDMs, RAW264.7 cells & M. bovis & $\begin{array}{l}\text { Inhibition of cABL to induce Akt/mTOR mediated autophagy and parkin } \\
\text { mediated xenophagy }\end{array}$ & $\begin{array}{l}\text { (Hussain et al., } \\
\text { 2019) }\end{array}$ \\
\hline Baicalin & RAW264.7 cells, PMs & Mtb H37Ra & $\begin{array}{l}\text { Inhibition of Akt/mTOR as well as Akt/NF-kB pathway, } \\
\text { Inhibition of NLRP3 inflammasome and IL-1 } \beta\end{array}$ & $\begin{array}{l}\text { (Zhang et al., } \\
\text { 2017) }\end{array}$ \\
\hline $\begin{array}{l}\text { Isoniazid- } \\
\text { incorporated Man-Se } \\
\text { NPs }\end{array}$ & THP-1 cells & $\begin{array}{l}\text { Mtb H37Rv, } M \\
\text { bovis BCG }\end{array}$ & $\begin{array}{l}\text { Inhibition of PI3K/Akt/mTOR signaling, } \\
\text { Upregulation of ROS production and inhibition of mitochondrial function }\end{array}$ & (Pi et al., 2020) \\
\hline Rapamycin & MSCs, THP-1 cells & Mtb H37Rv & $\begin{array}{l}\text { Elimination of actively replicating and latent bacteria with the combination of } \\
\text { antibiotics and rapamycin }\end{array}$ & $\begin{array}{l}\text { (Fatima et al., } \\
\text { 2020) }\end{array}$ \\
\hline $\begin{array}{l}\text { Rapamycin } \\
\text { microparticles }\end{array}$ & THP-1 cells & Mtb H37Rv & Increased uptake of rapamycin loaded PLGA particles targeting macrophages & $\begin{array}{l}\text { (Gupta et al., } \\
\text { 2014) }\end{array}$ \\
\hline
\end{tabular}

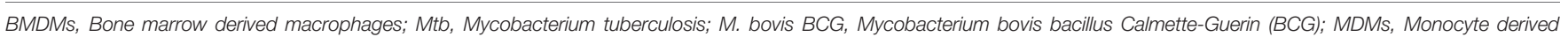

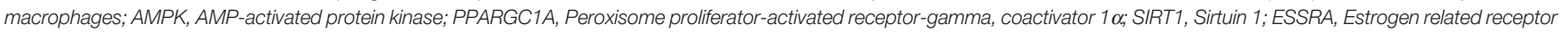

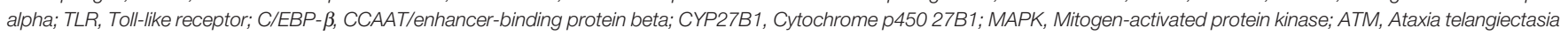

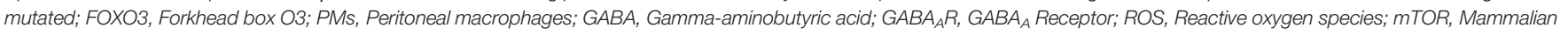

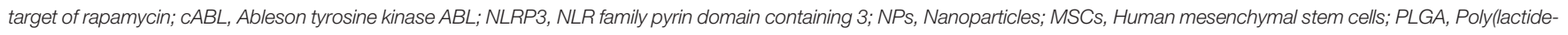
co-glycolide). 
Gibbons et al., 2009; Cerni et al., 2019; Zou et al., 2020), it is likely that these mTOR inhibitors have beneficial effects for antibacterial autophagy and host defense against Mtb infection. Future preclinical and clinical studies will clarify the precise role for several candidates of rapamycin analogs as a promising target for autophagy-based therapeutics against Mtb infection as well as other infectious diseases.

Indeed, pharmacological inhibitors of Akt/mTOR signaling, through regulation of autophagy, have emerged as promising approaches for therapeutics against cancers or liver diseases (Wang et al., 2019; Kaleagasioglu et al., 2020). Recent studies by using several drugs/agents that inhibit mTOR/Akt pathway have shed a light on autophagy-based antimicrobial therapy against Mtb or nontuberculous mycobacteria (NTM) infection. Bazedoxifene, a selective estrogen receptor modulator, promotes autophagy to suppress intracellular growth of Mtb through upregulation of ROS production and inhibition of Akt/mTOR signaling (Ouyang et al., 2020). Nilotinib, a tyrosine kinase inhibitor, induces xenophagy against $M$. bovis infection by inhibiting the PI3K/Akt/mTOR axis (Hussain et al., 2019). In addition, the herbal agent, baicalin, suppresses intracellular Mtb by inducing autophagy in murine macrophages via inhibition of Akt and mTOR phosphorylation (Zhang et al., 2017). However, targeting the mTORC1 pathway in patients co-infected with Mtb and human immunodeficiency virus (HIV) requires caution, because mTOR inhibition reduced phagosomal acidification and led to increased Mtb replication in co-infected conditions (Andersson et al., 2016). So far, most attempts by using mTOR/ Akt inhibitors focus on cancers (Kaleagasioglu et al., 2020). Future studies are needed to explore the potential or limitation of mTOR/Akt-targeted therapeutics against infections with antibiotic resistant Mtb or NTM. As cancers and Mtb infection share similar metabolic profiles (Shi et al., 2015; Gleeson et al., 2016), embracing an approach based on immunometabolic assessment will be crucial to develop future therapeutics which incorporate the inhibitors of Akt/mTOR signaling pathway, a major metabolic regulator (Covarrubias et al., 2015), into antimycobacterial activity evaluation.

Isoniazid-conjugated selenium (Se) nanoparticles (NPs) promote the fusion of Mtb to lysosomes and exert a synergistic effect on lysosomal and isoniazid-induced destruction of Mtb in macrophages ( $\mathrm{Pi}$ et al., 2020). Mechanistically, isoniazidconjugated Man-Se NPs promote autophagic degradation of Mtb through generation of intracellular ROS and inhibition of PI3K/Akt/mTOR pathway (Pi et al., 2020). Additionally, autophagy activation by rapamycin contribute to the elimination of Mtb in mesenchymal stem cells, which are important for dormancy (Fatima et al., 2020). Moreover, treatment of rapamycin, combined with isoniazid, promote sterile clearance and prevention of $\mathrm{TB}$ reactivation in vivo (Fatima et al., 2020). Together with the efficacy of inhalable rapamycin in clearing Mtb (Gupta et al., 2014), these findings suggest mTOR signaling pathway could be novel targets for adjunctive HDT against TB latency and reactivation. Autophagybased antimicrobial responses acting through mTOR/Akt are summarized in Table $\mathbf{1}$.

\section{WNT SIGNALING PATHWAY}

The Wnt/ $\beta$-catenin pathway, which is important for cell proliferation and polarity, is a target of bacterial virulence factors of invading intracellular pathogens, including Mtb (Villasenor et al., 2017; Ljungberg et al., 2019; Silva-Garcia et al., 2019). Meanwhile, the inhibitors of the $\mathrm{Wnt} / \beta$-catenin pathway used to treat cancers (Yan et al., 2017; Liu et al., 2019; Silva-Garcia et al., 2019) may have potential to control the pathological responses during chronic Mtb infection (Brandenburg and Reiling, 2016). However, it is just in its infancy to understand the precise roles of Wnt signaling in the context of autophagy pathway during mycobacterial infection.

Several studies reported that the Wnt signaling is linked to immune responses and autophagy pathways in terms of intracellular mycobacterial infection. The IL-1 family cytokine IL-36 $\gamma$ suppresses intracellular survival of Mtb by WNT5Adependent activation of autophagy in human monocyte-

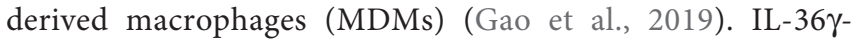
mediated autophagy activation is dependent on WNT5A expression in noncanonical Wnt pathway by regulating COX2/Akt/mTOR axis (Gao et al., 2019). In contrast, LKB1 inhibits intracellular Mtb by downregulating WNT5A and upregulating FOXO1 expression in human macrophages (Cui et al., 2019). Another study shows that Wnt3a, a ligand of Wnt signaling, suppresses BCG-induced autophagy through mTOR-dependent pathway and the expression of autophagy proteins such as LC3 in macrophages (Wu et al., 2019). Together, it has not been fully understood the clear role and mechanisms underlying Wnt signaling-mediated autophagy in regulating antibacterial host defense against Mtb infection. Given the multiple Wnt signaling molecules may play various roles in the different context of infection (Ljungberg et al., 2019; Rogan et al., 2019), future studies are warranted to understand the exact molecular mechanisms by which specific Wnt ligands and modulators regulate autophagy-mediated anti-mycobacterial activities in vivo as well as in vitro.

\section{TFEB}

Several transcription factors-such as TFEB, FOXO, and nuclear factor erythroid 2-related factor (NRF)-are downstream molecules of mTOR signaling (Schmeisser and Parker, 2019). Among them, TFEB, a member of the microphthalmia/ transcription factor E (MiT-TFE) family of basic helix-loophelix leucine-zipper transcription factors, is a key factor for lysosome biogenesis, energy homeostasis, and autophagy (Napolitano and Ballabio, 2016; Puertollano et al., 2018). The mTOR/Akt pathway regulates subcellular localization of TFEB by phosphorylating TFEB and binding to 14-3-3 protein, thereby inhibiting its nuclear translocation and activation (RoczniakFerguson et al., 2012; Napolitano and Ballabio, 2016; Puertollano et al., 2018). Interferon (IFN)- $\gamma$-induced autophagy is mediated through intracellular calcium-triggered activation of the phosphatase calcineurin (PPP3)-TFEB pathway, thus inhibiting 
mycobacterial survival in macrophages (Singh et al., 2018). PPAR $\alpha$ agonists promote autophagy and lysosomal gene activation (including TFEB) to enhance anti-mycobacterial defense (Kim Y. S. et al., 2017). In addition, TFEB controls excessive inflammatory responses during Mtb infection, because silencing of TFEB promotes proinflammatory cytokine synthesis in macrophages (Kim Y. S. et al., 2017). Furthermore, sirtuin 3 enhances antibacterial autophagy through TFEB expression during mycobacterial infection (Kim et al., 2019). The sirtuin 3 deficiency exaggerates immune pathology and in vivo bacterial burden during Mtb infection (Kim T. S. et al., 2019; Smulan et al., 2021). Sirtuin 3 activation by honokiol enhances antimicrobial responses through activation of antibacterial autophagy and amelioration of mitochondrial oxidative stress during $\mathrm{Mtb}$ infection (Kim T. S. et al., 2019). However, it is unclear whether sirutin 3-TFEB-mediated anti-inflammatory responses are directly associated with the host defense against Mtb.

Some antibiotics including linezolid and bedaquiline (BDQ) activate autophagy to promote clearance of Mtb (Genestet et al., 2018; Giraud-Gatineau et al., 2020). BDQ induces autophagy by upregulating lysosomal activation via TFEB and calcium signaling and potentiates the activity of other anti-TB drugs (GiraudGatineau et al., 2020). Ambroxol, a mucolytic agent identified by screening of autophagy-inducing drugs, promotes antimicrobial responses by inducing autophagy via nuclear translocation of TFEB (Choi S. W. et al., 2018). Together, these data suggest that TFEB plays a critical function in the activation of anti-mycobacterial responses to a variety of autophagy-activating agents and could be a principal target for developing autophagy-based therapeutics against TB.

\section{ANTIMICROBIAL PROTEINS: CATHELICIDINS}

Cathelicidin functions as an antimicrobial peptide and a second messenger in vitamin D-mediated antimicrobial responses, inflammation, and autophagy during Mtb infection (Jo, 2010; Chung et al., 2020). The expression of cathelicidin antimicrobial peptide (CAMP)/LL-37 and ATG expression in human macrophages is inhibited by Mtb (Rekha et al., 2015). A recent study shows that Mtb LprE suppresses cathelicidin expression via p38 MAPK pathway and inhibit autophagy in macrophages (Padhi et al., 2019). Indeed, the CAMP-mediated autophagy activation is importantly implicated in vitamin D-mediated host defense during Mtb infection (Liu et al., 2007; Yuk et al., 2009; Fabri et al., 2011; Rekha et al., 2015; Chung et al., 2020). Several innate immune signals including TLR2/1, TLR8, and cytokines are linked to regulation of cathelicidin/autophagy pathway to promote antimicrobial function (Shin et al., 2010b; Campbell and Spector, 2012; Yang et al., 2018; Padhi et al., 2019). Although these studies strongly suggest that cathelicidins play a critical role in autophagy as a second messenger, the exact mechanisms by which cathelicidins modulate the activation of autophagy are not clear.

Co-treatment of IL-12/IL-18 enhances anti-mycobacterial responses in human macrophages and lung epithelial cells in the context of IFN- $\gamma$-mediated immunity and the CAMP/ autophagy pathway (Yang et al., 2018). Thus, cathelicidins may function as critical mediators to linking innate and adaptive immune responses during Mtb infection (Chung et al., 2020). In addition, several factors should be considered to elucidate the host defensive function of cathelicidins during Mtb infection. For example, prostaglandin E2 (PGE2), a lipid mediator, impairs vitamin D3-induced cathelicidin expression and autophagy, thus promoting growth of Mtb in macrophages (Wan et al., 2018). Because vitamin D insufficiency is associated with susceptibility to TB (Talat et al., 2010; Pilarski et al., 2016; Nouri-Vaskeh et al., 2019), further knowledge on clinical application should be accumulated to clarify the efficacy of cathelicidins as adjuvants in HDTs against TB.

\section{INFLAMMATION}

Suppression of inflammation and tissue damage by modulating the host immune response are achieved through several modalities of HDTs against TB (Ahmed et al., 2020). During Mtb infection, inflammatory pathway is linked to autophagic defense in various ways. The combination of vitamin D3 and phenylbutyrate significantly decreases the levels of proinflammatory cytokines/chemokines in peripheral blood mononuclear cells (PBMCs) and increases the frequency of autophagy thereby exerting a favorable immunomodulatory effect (Rekha et al., 2018). Also, the herbal agent baicalin, an inducer of autophagy, inhibits NF- $\mathrm{B}$ signaling pathway and NLRP3 inflammasome activation, exerting an anti-inflammatory and antimicrobial effect (Zhang et al., 2017).

Although autophagy counteracts excessive inflammatory responses (Qian et al., 2017), its activation by lipopolysaccharide (LPS) restores Mtb-inhibited IL-12 production, promoting protective immunity (Fang et al., 2020). In addition, the C-type lectin receptor CLEC4E in association with TLR4 agonists (C4.T4) significantly improves antimicrobial host defense by activating MyD88-dependent autophagy and lysosomal biogenesis (Pahari et al., 2020). Importantly, C4.T4 agonists in combination with isoniazid or rifampicin kill intracellular $\mathrm{Mtb}$ to improve the efficacy of anti-TB drugs at lower dose than that of currently in use (Pahari et al., 2020). These studies suggest that, either by controlling excessive inflammation or inducing innate immune responses, activation of host-cell autophagy may contribute to the efficacy of anti-TB drugs during TB treatment. Future studies are needed to understand the exact mechanisms by which autophagytargeting drugs/agents shape the profile of inflammatory responses during Mtb infection to impact host defensive function.

\section{ENDOPLASMIC RETICULUM STRESS AND MYCOBACTERIAL INFECTION}

ER homeostasis is mediated by the unfolded protein response (UPR), which involves IRE1/sXBP1, PERK/EIf2, and ATF6 (Tameire et al., 2015). Dysregulation of ER homeostasis is 
associated with ER stress and leads to various diseases including autoimmune diseases and skin related pathologies (Junjappa et al., 2018; Park et al., 2019). The ER stress response is linked to innate immune signaling, lipid accumulation, and proinflammatory responses in myeloid-lineage cells during infection and inflammation (Martinon and Glimcher, 2011; Yao et al., 2014; Di Conza and Ho, 2020; Sukhorukov et al., 2020). Mtb and its components trigger ER stress to modulate host cell death, intracellular survival, and inflammatory responses (Lim et al., 2016; Jo et al., 2017; Lee et al., 2019). Indeed, activation of autophagy by the ER stress response is related to cytoprotection, particularly in tumor cells (Rouschop et al., 2010; Hart et al., 2012; Bhardwaj et al., 2019). It is warranted to study whether regulation of autophagy in the connection with UPR and/or ER stress may also exert a beneficial effect in modulating the pathological responses induced by Mtb infection.

ER stress and autophagy are linked together during Mtb infection, although the precise molecular mechanisms are largely unknown. BAG2 (BCL2-associated athanogene 2), a protein associated with cell fate determination, promotes autophagic flux and reticulophagy by enhancing SQSTM1/p62 localization to the ER and contributes to host cell resistance to Mtb-mediated damage (Liang et al., 2020). Mechanistically, BAG2-induced autophagy activation involves ERK-mediated dissociation of Beclin-1 (BECN1)-BCL2 complex, and XBP1induced transcriptional activation (Liang et al., 2020). These data suggest that BAG2 promotes antimicrobial defense against Mtb infection by linking ER stress and selective autophagy (Liang et al., 2020). In addition, ajoene, a garlic-derived sulfurcontaining compound, exerts an anti-mycobacterial effect by activating autophagy and ER stress (Choi J. A. et al., 2018). Ajoene-mediated JNK activation and ROS production contributes to the activation of ER stress, autophagy, and antimycobacterial effects (Choi J. A. et al., 2018). These studies suggest that ER stress and autophagy pathways are interconnected for anti-mycobacterial host defense, yet many challenging questions remain about the cross talks between ER stress and autophagy, both are crucial in the maintenance of intracellular protein homeostasis (Rashid et al., 2015). Additional functional analyses are needed to elucidate the roles and molecular mechanisms underlying that ER stress interacts with autophagy pathway during mycobacterial infection.

\section{MISCELLANEOUS AND UNKNOWN MECHANISMS}

Substantial evidences exist that several autophagy-activating agents effectively increase transcriptional activation of ATGs and nonspecific enhancement of autophagy. Phenotypic wholecell screening using $M$. bovis BCG showed that 5-nitro-1,10phenanthroline (5NP) inhibits intracellular Mtb, at least in part by activating autophagy and increasing BECN1 and ATG3 expression (Kidwai et al., 2017). In addition, the bovine antimicrobial peptide lactoferrin killed $M$. avium and enhanced the anti-mycobacterial effect of ethambutol in host cells by promoting formation of autophagosomes and lysosomes (Silva et al., 2017). Everolimus, a derivative of rapamycin, not only inhibits mTORC1 and promotes autophagy, but enhances immunity in elderly at low doses (Mannick et al., 2014), suggesting therapeutic potential for TB (Cerni et al., 2019). Future studies are needed to clarify whether everolimus at appropriate doses has a protective effect in host defense against Mtb infection, particularly in elderly, through activation of autophagy.

There is considerable interest in the development of combination treatment strategies based on autophagyactivating molecules/agents incorporating the currently used anti-TB drugs. Recent study showed that the pyrazole derivative small molecule, NSC 18725, inhibits growth of intracellular $\mathrm{Mtb}$ and exerts a synergistic effect with isoniazid (Arora et al., 2019). Also, NSC 18725-mediated activation of autophagy induces an antimicrobial response to intracellular Mtb and other fast-growing mycobacteria (Arora et al., 2019). However, the exact mechanism by which NSC 18725 induces autophagy and anti-mycobacterial effect is yet to be elucidated.

A recent study demonstrated that autophagy-activating agents have the adjuvant effect of vaccines. Curcumin NPs are promising adjuvants for TB vaccines, because curcumin NPmediated antigen-presenting cell functions, including autophagy activation, contribute to induction of long-lasting central memory $\mathrm{T}$ cells by the BCG vaccine (Ahmad et al., 2019). Although the impact of autophagy in the development of adjuvants and vaccines is largely unknown, it is an exciting area of potentially high clinical relevance for prevention of TB. Autophagy-based antimicrobial responses targeting several mechanisms other than AMPK and mTOR pathways are summarized in Table 2.

\section{CONCLUSION}

The therapeutic and preventative efficacy of autophagyactivating agents for Mtb infection have been investigated extensively. As more agents/molecules activating the autophagy are identified, we face the challenge of understanding the underlying molecular mechanisms. These agents/molecules act through several mechanisms such as AMPK and mTOR pathways, TFEB, cathelicidins, inflammation, ER stress, and ATGs to ultimately modulate the autophagy processes and the anti-mycobacterial responses (Tables 1 and 2). Future studies will clarify whether many of those agents have the effects to increase the efficacy of anti-TB drugs in pre-clinical and clinical models. It is possible that several of these pathways function together and/or that key regulators of multiple signaling pathways cooperate in the activation of autophagy-targeted antimicrobial responses to Mtb infection. Such knowledge will facilitate development of therapeutics and vaccines for Mtb infection. In addition, the clinical relevance of in vitro findings on autophagy-based antimicrobial strategies against Mtb infection needs to be established. 
TABLE 2 | Autophagy-based antimicrobial responses against mycobacterial infections.

\begin{tabular}{|c|c|c|c|c|c|}
\hline Target & Activator & Study model & Pathogen & Mechanism & Ref. \\
\hline \multirow[t]{2}{*}{ WNT5A } & 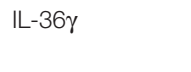 & Human MDMs & $\begin{array}{l}\text { Mtb H37Rv, } \\
\text { M. bovis BCG }\end{array}$ & Autophagy activation via COX-2/AKT/mTOR axis & (Gao et al., 2019) \\
\hline & LKB1 & THP-1 \& U937 cells & Mtb H37Rv & Upregulation of FOXO1 expression & (Cui et al., 2019) \\
\hline Wnt3a & - & RAW264.7 cells & M. bovis BCG & $\begin{array}{l}\text { Autophagy inhibition by activating mTOR-dependent } \\
\text { pathways }\end{array}$ & (Wu et al., 2019) \\
\hline \multirow[t]{4}{*}{ TFEB } & $\mathrm{IFN}-\gamma$ & $\begin{array}{l}\text { RAW264.7 cells, } \\
\text { C57BL/6 mice }\end{array}$ & Mtb H37Rv & $\begin{array}{l}\text { Nuclear translocation of TFEB through PPP3 in an } \\
\text { HMOX1-dependent manner }\end{array}$ & (Singh et al., 2018) \\
\hline & $\begin{array}{l}\text { PPAR- } \alpha \\
\text { activation }\end{array}$ & BMDMs, C57BL/6 mice & $\begin{array}{l}\text { Mtb H37Rv, } \\
\text { M. bovis BCG }\end{array}$ & Promotion of TFEB-mediated autophagy & $\begin{array}{l}\text { (Kim Y. S. et al., } \\
2017)\end{array}$ \\
\hline & $\mathrm{BDQ}$ & Human MDMs & Mtb H37Rv & $\begin{array}{l}\text { Upregulation of lysosmal activation via TFEB and calcium } \\
\text { signaling }\end{array}$ & $\begin{array}{l}\text { (Giraud-Gatineau } \\
\text { et al., 2020) }\end{array}$ \\
\hline & Ambroxol & BMDMs & Mtb Erdman & Induction of LC3B puncta and TFEB nuclear translocation & $\begin{array}{l}\text { (Choi S. W. et al., } \\
\text { 2018) }\end{array}$ \\
\hline \multirow[t]{2}{*}{ Cathelicidins } & IL-12/IL-18 & $\begin{array}{l}\text { THP-1 \& A549 cells, } \\
\text { human MDMs }\end{array}$ & M. bovis BCG & Induction of VDR-derived cathelicidin and autophagy & (Yang et al., 2018) \\
\hline & PGE2 & $\begin{array}{l}\text { MM6 cells, human } \\
\text { MDMs }\end{array}$ & Mtb H37Rv & $\begin{array}{l}\text { Inhibition of vitamin D3-induced cathelicidin and } \\
\text { autophagy via EP2/EP4 }\end{array}$ & (Wan et al., 2018) \\
\hline \multirow[t]{3}{*}{ Inflammation } & $\begin{array}{l}\text { Vitamin D } \\
\text { +Phenylbutyrate }\end{array}$ & Human PBMCs & Mtb H37Rv & Reduction of proinflammatory cytokines/chemokines & (Rekha et al., 2018) \\
\hline & LPS & THP-1 cells & Mtb H37Ra & $\begin{array}{l}\text { Restoration of Mtb-inhibited IL-12 synthesis and secretion } \\
\text { via autophagy activation }\end{array}$ & (Fang et al., 2020) \\
\hline & C4.T4 & BMDMs, C57BL/6 mice & Mtb H37Rv, H37Ra & $\begin{array}{l}\text { Induction of autophagy via Myd88-dependent/mTOR- } \\
\text { independent PI3K activation }\end{array}$ & (Pahari et al., 2020) \\
\hline \multirow[t]{2}{*}{ ER Stress } & BAG2 & $\begin{array}{l}\text { BMDMs, RAW264.7 } \\
\text { cells }\end{array}$ & Mtb H37Ra & $\begin{array}{l}\text { Reduction of ER-stress-induced apoptosis through } \\
\text { selective autophagy }\end{array}$ & (Liang et al., 2020) \\
\hline & Ajoene & RAW264.7 cells & Mtb H37Rv & ER stress mediated ROS production and JNK activation & $\begin{array}{l}\text { (Choi J. A. et al., } \\
\text { 2018) }\end{array}$ \\
\hline \multirow[t]{4}{*}{ Miscellaneous } & $5 \mathrm{NP}$ & THP-1 cells & $\begin{array}{l}\text { M. bovis BCG, } \\
\text { M. smegmatis }\end{array}$ & $\begin{array}{l}\text { Activation of autophagy with increased expression of } \\
\text { BECN1 and ATG3 }\end{array}$ & (Kidwai et al., 2017) \\
\hline & Lactoferrin & BMDMs & M. avium & $\begin{array}{l}\text { Increased formation of lysosomes and autophagosome- } \\
\text { like vesicle }\end{array}$ & (Silva et al., 2017) \\
\hline & NSC 18725 & THP-1 cells & $\begin{array}{l}\text { M. bovis BCG, } \\
\text { M. smegmatis }\end{array}$ & $\begin{array}{l}\text { Induction of autophagy with upregulation of BECN1 and } \\
\text { ATG3 }\end{array}$ & (Arora et al., 2019) \\
\hline & Curcumin NPs & PMs, C57BL/6 mice & $\begin{array}{l}\text { Mtb H37Rv, } \\
\text { M. bovis BCG }\end{array}$ & $\begin{array}{l}\text { Enhancement of autophagy and antigen presenting } \\
\text { capacity of APCs }\end{array}$ & $\begin{array}{l}\text { (Ahmad et al., } \\
\text { 2019) }\end{array}$ \\
\hline
\end{tabular}

IL-36, Interleukin-36; MDMs, Monocyte derived macrophages; Mtb, Mycobacterium tuberculosis; M. bovis BCG, Mycobacterium bovis bacillus Calmette-Guerin (BCG); COX-2, Cyclooxygenase-2; LKB1, Liver kinase B1; FOXO1, Forkhead box protein O1; IFN, Interferon; TFEB, Transcription factor EB; PPP3, Protein phosphatase 3; HMOX1, Heme oxygenase 1; PPAR, Peroxisome proliferator-activated receptor; BMDMs, Bone marrow derived macrophages; BDQ, Bedaquiline; VDR, Vitamin D receptor; PGE2, Prostaglandin E2; EP, E prostanoid; PBMC, Peripheral blood mononuclear cells; C4.T4, Agonists of CLEC4E (C4/TDB) and TLR4 (T4/ultra-pure-LPS); Myd88, Myeloid differentiation primary response 88; PI3K, Phosphoinositide 3-kinases; BAG2, BCL2-associated athanogene 2; ER, Endoplasmic reticulum; JNK, C-Jun N-terminal kinases; 5NP, 5-Nitro-1,10-phenanthroline; NPS, Nanoparticles; PMs, Peritoneal macrophages; APC, Antigen presenting cells.

\section{AUTHOR CONTRIBUTIONS}

E-KJ designed the study. E-KJ, TY, SP, JKK, and PS wrote and reviewed the manuscript. JKK prepared the figure; SP and PS summarized the tables. All authors contributed to the article and approved the submitted version.

\section{FUNDING}

This work was supported by the National Research Foundation of Korea (NRF) grant funded by the Korea government (MSIT)

\section{REFERENCES}

Ahmad, S., Bhattacharya, D., Kar, S., Ranganathan, A., Van Kaer, L., and Das, G. (2019). Curcumin Nanoparticles Enhance Mycobacterium bovis BCG Vaccine Efficacy by Modulating Host Immune Responses. Infect. Immun. 87 (11), e00291-19. doi: 10.1128/IAI.00291-19
(No.2019R1A2C1087686) and by the framework of international cooperation program managed by National Research Foundation of Korea (Grant Number:2015K2A2A6002008).

\section{ACKNOWLEDGMENTS}

We are indebted to current and past members of our Medical Research Center (i-MRC) for discussions and investigations that contributed to this article. We apologize to colleagues whose work and publications could not be referenced owing to space constraints.

Ahmed, S., Raqib, R., Guethmundsson, G. H., Bergman, P., Agerberth, B., and Rekha, R. S. (2020). Host-Directed Therapy as a Novel Treatment Strategy to Overcome Tuberculosis: Targeting Immune Modulation. Antibiot. (Basel) 9 (1), 21. doi: 10.3390/antibiotics9010021

Andersson, A. M., Andersson, B., Lorell, C., Raffetseder, J., Larsson, M., and Blomgran, R. (2016). Autophagy induction targeting mTORC1 enhances 
Mycobacterium tuberculosis replication in HIV co-infected human macrophages. Sci. Rep. 6, 28171. doi: 10.1038/srep28171

Arora, G., Gagandeep,, Behura, A., Gosain, T. P., Shaliwal, R. P., Kidwai, S., et al. (2019). NSC 18725, a Pyrazole Derivative Inhibits Growth of Intracellular Mycobacterium tuberculosis by Induction of Autophagy. Front. Microbiol. 10, 3051. doi: $10.3389 /$ fmicb.2019.03051

Batista, L. A. F., Silva, K. J. S., da Costa, E. S. L. M., de Moura, Y. F., and Zucchi, F. C. R. (2020). Tuberculosis: A granulomatous disease mediated by epigenetic factors. Tuberculosis (Edinb) 123, 101943. doi: 10.1016/j.tube.2020.101943

Bergman, P., Raqib, R., Rekha, R. S., Agerberth, B., and Gudmundsson, G. H. (2020). Host Directed Therapy Against Infection by Boosting Innate Immunity. Front. Immunol. 11, 1209. doi: 10.3389/fimmu.2020.01209

Bhardwaj, M., Leli, N. M., Koumenis, C., and Amaravadi, R. K. (2019). Regulation of autophagy by canonical and non-canonical ER stress responses. Semin. Cancer Biol. 66, 116-128. doi: 10.1016/j.semcancer.2019.11.007

Brandenburg, J., and Reiling, N. (2016). The Wnt Blows: On the Functional Role of Wnt Signaling in Mycobacterium tuberculosis Infection and Beyond. Front. Immunol. 7, 635. doi: 10.3389/fimmu.2016.00635

Campbell, G. R., and Spector, S. A. (2012). Toll-like receptor 8 ligands activate a vitamin $\mathrm{D}$ mediated autophagic response that inhibits human immunodeficiency virus type 1. PloS Pathog. 8 (11), e1003017. doi: 10.1371/ journal.ppat.1003017

Cerni, S., Shafer, D., To, K., and Venketaraman, V. (2019). Investigating the Role of Everolimus in mTOR Inhibition and Autophagy Promotion as a Potential Host-Directed Therapeutic Target in Mycobacterium tuberculosis Infection. J. Clin. Med. 8 (2), 232. doi: 10.3390/jcm8020232

Chai, Q., Wang, X., Qiang, L., Zhang, Y., Ge, P., Lu, Z., et al. (2019). A Mycobacterium tuberculosis surface protein recruits ubiquitin to trigger host xenophagy. Nat. Commun. 10 (1), 1973. doi: 10.1038/s41467-019-09955-8

Chai, Q., Wang, L., Liu, C. H., and Ge, B. (2020). New insights into the evasion of host innate immunity by Mycobacterium tuberculosis. Cell Mol. Immunol. 17 (9), 901-913. doi: 10.1038/s41423-020-0502-z

Chandra, P., and Kumar, D. (2016). Selective autophagy gets more selective: Uncoupling of autophagy flux and xenophagy flux in Mycobacterium tuberculosis-infected macrophages. Autophagy 12 (3), 608-609. doi: 10.1080/ 15548627.2016.1139263

Chandra, P., Ghanwat, S., Matta, S. K., Yadav, S. S., Mehta, M., Siddiqui, Z., et al. (2015). Mycobacterium tuberculosis Inhibits RAB7 Recruitment to Selectively Modulate Autophagy Flux in Macrophages. Sci. Rep. 5:16320. doi: 10.1038/srep16320

Chen, D. Y., Chen, Y. M., Lin, C. F., Lo, C. M., Liu, H. J., and Liao, T. L. (2020). MicroRNA-889 Inhibits Autophagy To Maintain Mycobacterial Survival in Patients with Latent Tuberculosis Infection by Targeting TWEAK. mBio 11 (1), e03045-19. doi: 10.1128/mBio.03045-19

Choi, J. A., Cho, S. N., Lim, Y. J., Lee, J., Go, D., Kim, S. H., et al. (2018). Enhancement of the antimycobacterial activity of macrophages by ajoene. Innate Immun. 24 (1), 79-88. doi: 10.1177/1753425917747975

Choi, S. W., Gu, Y., Peters, R. S., Salgame, P., Ellner, J. J., Timmins, G. S., et al. (2018). Ambroxol Induces Autophagy and Potentiates Rifampin Antimycobacterial Activity. Antimicrob. Agents Chemother. 62 (9), e0101918. doi: 10.1128/AAC.01019-18

Chung, C., Silwal, P., Kim, I., Modlin, R. L., and Jo, E. K. (2020). Vitamin DCathelicidin Axis: at the Crossroads between Protective Immunity and Pathological Inflammation during Infection. Immune Netw. 20 (2), e12. doi: 10.4110/in.2020.20.e12

Covarrubias, A. J., Aksoylar, H. I., and Horng, T. (2015). Control of macrophage metabolism and activation by mTOR and Akt signaling. Semin. Immunol. 27 (4), 286-296. doi: 10.1016/j.smim.2015.08.001

Cui, J., Li, M., Liu, W., Zhang, B., Sun, B., Niu, W., et al. (2019). Liver kinase B1 overexpression controls mycobacterial infection in macrophages via FOXO1/ Wnt5a signaling. J. Cell Biochem. 120 (1), 224-231. doi: 10.1002/jcb.27322

Deretic, V. (2008). Autophagy, an immunologic magic bullet: Mycobacterium tuberculosis phagosome maturation block and how to bypass it. Future Microbiol. 3 (5), 517-524. doi: 10.2217/17460913.3.5.517

Di Conza, G., and Ho, P. C. (2020). ER Stress Responses: An Emerging Modulator for Innate Immunity. Cells 9 (3), 695. doi: 10.3390/cells9030695

Ding, R., Wu, W., Sun, Z., and Li, Z. (2020). AMP-activated protein kinase: An attractive therapeutic target for ischemia-reperfusion injury. Eur. J. Pharmacol. 888, 173484. doi: 10.1016/j.ejphar.2020.173484
Fabri, M., Stenger, S., Shin, D. M., Yuk, J. M., Liu, P. T., Realegeno, S., et al. (2011). Vitamin D is required for IFN-gamma-mediated antimicrobial activity of human macrophages. Sci. Transl. Med. 3 (104), 104ra102. doi: 10.1126/ scitranslmed.3003045

Fang, F., Ge, Q., Li, R., Lv, J., Zhang, Y., Feng, A., et al. (2020). LPS restores protective immunity in macrophages against Mycobacterium tuberculosis via autophagy. Mol. Immunol. 124, 18-24. doi: 10.1016/j.molimm.2020.05.001

Fatima, S., Kamble, S. S., Dwivedi, V. P., Bhattacharya, D., Kumar, S., Ranganathan, A., et al. (2020). Mycobacterium tuberculosis programs mesenchymal stem cells to establish dormancy and persistence. J. Clin. Invest. 130 (2), 655-661. doi: 10.1172/JCI128043

Franco, L. H., Nair, V. R., Scharn, C. R., Xavier, R. J., Torrealba, J. R., Shiloh, M. U., et al. (2017). The Ubiquitin Ligase Smurf1 Functions in Selective Autophagy of Mycobacterium tuberculosis and Anti-tuberculous Host Defense. Cell Host Microbe 21 (1), 59-72. doi: 10.1016/j.chom.2016.11.002

Gao, Y., Wen, Q., Hu, S., Zhou, X., Xiong, W., Du, X., et al. (2019). IL-36gamma Promotes Killing of Mycobacterium tuberculosis by Macrophages via WNT5AInduced Noncanonical WNT Signaling. J. Immunol. 203 (4), 922-935. doi: $10.4049 /$ jimmunol.1900169

Genestet, C., Bernard-Barret, F., Hodille, E., Ginevra, C., Ader, F., Goutelle, S., et al. (2018). Antituberculous drugs modulate bacterial phagolysosome avoidance and autophagy in Mycobacterium tuberculosis-infected macrophages. Tuberculosis (Edinb) 111, 67-70. doi: 10.1016/j.tube.2018.05.014

Gibbons, J. J., Abraham, R. T., and Yu, K. (2009). Mammalian target of rapamycin: discovery of rapamycin reveals a signaling pathway important for normal and cancer cell growth. Semin. Oncol. 36 Suppl 3, S3-S17. doi: 10.1053/ j.seminoncol.2009.10.011

Giraud-Gatineau, A., Coya, J. M., Maure, A., Biton, A., Thomson, M., Bernard, E. M., et al. (2020). The antibiotic bedaquiline activates host macrophage innate immune resistance to bacterial infection. Elife 9, e55692. doi: 10.7554/ eLife. 55692

Gleeson, L. E., Sheedy, F. J., Palsson-McDermott, E. M., Triglia, D., O’Leary, S. M., O'Sullivan, M. P., et al. (2016). Cutting Edge: Mycobacterium tuberculosis Induces Aerobic Glycolysis in Human Alveolar Macrophages That Is Required for Control of Intracellular Bacillary Replication. J. Immunol. 196 (6), 24442449. doi: 10.4049/jimmunol.1501612

Glick, D., Barth, S., and Macleod, K. F. (2010). Autophagy: cellular and molecular mechanisms. J. Pathol. 221 (1), 3-12. doi: 10.1002/path.2697

Gomes, L. C., and Dikic, I. (2014). Autophagy in antimicrobial immunity. Mol. Cell 54 (2), 224-233. doi: 10.1016/j.molcel.2014.03.009

Gupta, A., Pant, G., Mitra, K., Madan, J., Chourasia, M. K., and Misra, A. (2014). Inhalable particles containing rapamycin for induction of autophagy in macrophages infected with Mycobacterium tuberculosis. Mol. Pharm. 11 (4), 1201-1207. doi: 10.1021/mp4006563

Gupta, A., Misra, A., and Deretic, V. (2016). Targeted pulmonary delivery of inducers of host macrophage autophagy as a potential host-directed chemotherapy of tuberculosis. Adv. Drug Delivery Rev. 102, 10-20. doi: 10.1016/j.addr.2016.01.016

Gutierrez, M. G., Master, S. S., Singh, S. B., Taylor, G. A., Colombo, M. I., and Deretic, V. (2004). Autophagy is a defense mechanism inhibiting BCG and Mycobacterium tuberculosis survival in infected macrophages. Cell 119 (6), 753-766. doi: 10.1016/j.cell.2004.11.038

Hart, L. S., Cunningham, J. T., Datta, T., Dey, S., Tameire, F., Lehman, S. L., et al. (2012). ER stress-mediated autophagy promotes Myc-dependent transformation and tumor growth. J. Clin. Invest. 122 (12), 4621-4634. doi: 10.1172/JCI62973

Hussain, T., Zhao, D., Shah, S. Z. A., Sabir, N., Wang, J., Liao, Y., et al. (2019). Nilotinib: A Tyrosine Kinase Inhibitor Mediates Resistance to Intracellular Mycobacterium Via Regulating Autophagy. Cells 8 (5), 506. doi: 10.3390/ cells8050506

Jhanwar-Uniyal, M., Wainwright, J. V., Mohan, A. L., Tobias, M. E., Murali, R., Gandhi, C. D., et al. (2019). Diverse signaling mechanisms of mTOR complexes: mTORC1 and mTORC2 in forming a formidable relationship. Adv. Biol. Regul. 72, 51-62. doi: 10.1016/j.jbior.2019.03.003

Jiao, Y., and Sun, J. (2019). Bacterial Manipulation of Autophagic Responses in Infection and Inflammation. Front. Immunol. 10, 2821. doi: 10.3389/ fimmu. 2019.02821

Jo, S. H., Choi, J. A., Lim, Y. J., Lee, J., Cho, S. N., Oh, S. M., et al. (2017). Calreticulin modulates the intracellular survival of mycobacteria by regulating 
ER-stress-mediated apoptosis. Oncotarget 8 (35), 58686-58698. doi: 10.18632/ oncotarget.17419

Jo, E. K. (2010). Innate immunity to mycobacteria: vitamin D and autophagy. Cell Microbiol. 12 (8), 1026-1035. doi: 10.1111/j.1462-5822.2010.01491.x

Junjappa, R. P., Patil, P., Bhattarai, K. R., Kim, H. R., and Chae, H. J. (2018). IRE1alpha Implications in Endoplasmic Reticulum Stress-Mediated Development and Pathogenesis of Autoimmune Diseases. Front. Immunol. 9, 1289. doi: $10.3389 /$ fimmu.2018.01289

Kaleagasioglu, F., Ali, D. M., and Berger, M. R. (2020). Multiple Facets of Autophagy and the Emerging Role of Alkylphosphocholines as Autophagy Modulators. Front. Pharmacol. 11, 547. doi: 10.3389/fphar.2020.00547

Kaur, A., and Sharma, S. (2017). Mammalian target of rapamycin (mTOR) as a potential therapeutic target in various diseases. Inflammopharmacology 25 (3), 293-312. doi: 10.1007/s10787-017-0336-1

Kidwai, S., Park, C. Y., Mawatwal, S., Tiwari, P., Jung, M. G., Gosain, T. P., et al. (2017). Dual Mechanism of Action of 5-Nitro-1,10-Phenanthroline against Mycobacterium tuberculosis. Antimicrob. Agents Chemother. 61 (11), e0096917. doi: 10.1128/AAC.00969-17

Kim, J. K., Yuk, J. M., Kim, S. Y., Kim, T. S., Jin, H. S., Yang, C. S., et al. (2015). MicroRNA-125a Inhibits Autophagy Activation and Antimicrobial Responses during Mycobacterial Infection. J. Immunol. 194 (11), 5355-5365. doi: 10.4049/ jimmunol.1402557

Kim, J. K., Kim, Y. S., Lee, H. M., Jin, H. S., Neupane, C., Kim, S., et al. (2018). GABAergic signaling linked to autophagy enhances host protection against intracellular bacterial infections. Nat. Commun. 9 (1), 4184. doi: 10.1038/ s41467-018-06487-5

Kim, S. Y., Yang, C. S., Lee, H. M., Kim, J. K., Kim, Y. S., Kim, Y. R., et al. (2018). ESRRA (estrogen-related receptor alpha) is a key coordinator of transcriptional and post-translational activation of autophagy to promote innate host defense. Autophagy 14 (1), 152-168. doi: 10.1080/15548627.2017.1339001

Kim, J. K., Kim, T. S., Basu, J., and Jo, E. K. (2017). MicroRNA in innate immunity and autophagy during mycobacterial infection. Cell Microbiol. 19 (1), e12687. doi: $10.1111 / \mathrm{cmi} .12687$

Kim, T. S., Jin, Y. B., Kim, Y. S., Kim, S., Kim, J. K., Lee, H. M., et al. (2019). SIRT3 promotes antimycobacterial defenses by coordinating mitochondrial and autophagic functions. Autophagy 15 (8), 1356-1375. doi: 10.1080/ 15548627.2019 .1582743

Kim, Y. S., Lee, H. M., Kim, J. K., Yang, C. S., Kim, T. S., Jung, M., et al. (2017). PPAR-alpha Activation Mediates Innate Host Defense through Induction of TFEB and Lipid Catabolism. J. Immunol. 198 (8), 3283-3295. doi: 10.4049/ jimmunol.1601920

Kim, Y. S., Silwal, P., Kim, S. Y., Yoshimori, T., and Jo, E. K. (2019). Autophagyactivating strategies to promote innate defense against mycobacteria. Exp. Mol. Med. 51 (12), 1-10. doi: 10.1038/s12276-019-0290-7

Kimmey, J. M., Huynh, J. P., Weiss, L. A., Park, S., Kambal, A., Debnath, J., et al. (2015). Unique role for ATG5 in neutrophil-mediated immunopathology during $M$. tuberculosis infection. Nature 528 (7583), 565-569. doi: 10.1038/ nature16451

Koster, S., Upadhyay, S., Chandra, P., Papavinasasundaram, K., Yang, G., Hassan, A., et al. (2017). Mycobacterium tuberculosis is protected from NADPH oxidase and LC3-associated phagocytosis by the LCP protein CpsA. Proc. Natl. Acad. Sci. U.S.A. 114 (41), E8711-E8720. doi: 10.1073/pnas.1707792114

Kumar, R., Sahu, S. K., Kumar, M., Jana, K., Gupta, P., Gupta, U. D., et al. (2016). MicroRNA 17-5p regulates autophagy in Mycobacterium tuberculosis-infected macrophages by targeting Mcl-1 and STAT3. Cell Microbiol. 18 (5), 679-691. doi: $10.1111 / \mathrm{cmi} .12540$

Lazarou, M., Sliter, D. A., Kane, L. A., Sarraf, S. A., Wang, C., Burman, J. L., et al. (2015). The ubiquitin kinase PINK1 recruits autophagy receptors to induce mitophagy. Nature 524 (7565), 309-314. doi: 10.1038/nature14893

Lee, J., Choi, J. A., Cho, S. N., Son, S. H., and Song, C. H. (2019). Mitofusin 2Deficiency Suppresses Mycobacterium tuberculosis Survival in Macrophages. Cells 8 (11), 1355. doi: 10.3390/cells8111355

Li, J., Kim, S. G., and Blenis, J. (2014). Rapamycin: one drug, many effects. Cell Metab. 19 (3), 373-379. doi: 10.1016/j.cmet.2014.01.001

Li, T., Mu, N., Yin, Y., Yu, L., and Ma, H. (2020). Targeting AMP-Activated Protein Kinase in Aging-Related Cardiovascular Diseases. Aging Dis. 11 (4), 967-977. doi: 10.14336/AD.2019.0901
Liang, S., Wang, F., Bao, C., Han, J., Guo, Y., Liu, F., et al. (2020). BAG2 ameliorates endoplasmic reticulum stress-induced cell apoptosis in Mycobacterium tuberculosis-infected macrophages through selective autophagy. Autophagy 16 (8), 1453-1467. doi: 10.1080/15548627. 2019.1687214

Lim, Y. J., Yi, M. H., Choi, J. A., Lee, J., Han, J. Y., Jo, S. H., et al. (2016). Roles of endoplasmic reticulum stress-mediated apoptosis in M1-polarized macrophages during mycobacterial infections. Sci. Rep. 6, 37211. doi: $10.1038 /$ srep 37211

Liu, P. T., Stenger, S., Tang, D. H., and Modlin, R. L. (2007). Cutting edge: vitamin D-mediated human antimicrobial activity against Mycobacterium tuberculosis is dependent on the induction of cathelicidin. J. Immunol. 179 (4), 2060-2063. doi: 10.4049/jimmunol.179.4.2060

Liu, D., Chen, L., Zhao, H., Vaziri, N. D., Ma, S. C., and Zhao, Y. Y. (2019). Small molecules from natural products targeting the Wnt/beta-catenin pathway as a therapeutic strategy. BioMed. Pharmacother. 117, 108990. doi: 10.1016/ j.biopha.2019.108990

Ljungberg, J. K., Kling, J. C., Tran, T. T., and Blumenthal, A. (2019). Functions of the WNT Signaling Network in Shaping Host Responses to Infection. Front. Immunol. 10, 2521. doi: 10.3389/fimmu.2019.02521

Maiti, D., Bhattacharyya, A., and Basu, J. (2001). Lipoarabinomannan from Mycobacterium tuberculosis promotes macrophage survival by phosphorylating Bad through a phosphatidylinositol 3-kinase/Akt pathway. J. Biol. Chem. 276 (1), 329-333. doi: 10.1074/jbc.M002650200

Mannick, J. B., Del Giudice, G., Lattanzi, M., Valiante, N. M., Praestgaard, J., Huang, B., et al. (2014). mTOR inhibition improves immune function in the elderly. Sci. Transl. Med. 6 (268), 268ra179. doi: 10.1126/scitranslmed.3009892

Manzanillo, P. S., Ayres, J. S., Watson, R. O., Collins, A. C., Souza, G., Rae, C. S., et al. (2013). The ubiquitin ligase parkin mediates resistance to intracellular pathogens. Nature 501 (7468), 512-516. doi: 10.1038/nature12566

Martinez, J., Malireddi, R. K., Lu, Q., Cunha, L. D., Pelletier, S., Gingras, S., et al. (2015). Molecular characterization of LC3-associated phagocytosis reveals distinct roles for Rubicon, NOX2 and autophagy proteins. Nat. Cell Biol. 17 (7), 893-906. doi: 10.1038/ncb3192

Martinon, F., and Glimcher, L. H. (2011). Regulation of innate immunity by signaling pathways emerging from the endoplasmic reticulum. Curr. Opin. Immunol. 23 (1), 35-40. doi: 10.1016/j.coi.2010.10.016

Mendes, A. C., Ciccone, M., Gazolla, B., and Bahia, D. (2020). Epithelial Haven and Autophagy Breakout in Gonococci Infection. Front. Cell Dev. Biol. 8, 439. doi: $10.3389 /$ fcell.2020.00439

Napolitano, G., and Ballabio, A. (2016). TFEB at a glance. J. Cell Sci. 129 (13), 2475-2481. doi: 10.1242/jcs. 146365

Nouri-Vaskeh, M., Sadeghifard, S., Saleh, P., Farhadi, J., Amraii, M., and Ansarin, K. (2019). Vitamin D Deficiency among Patients with Tuberculosis: a CrossSectional Study in Iranian-Azari Population. Tanaffos 18 (1), 11-17.

Ouimet, M., Koster, S., Sakowski, E., Ramkhelawon, B., van Solingen, C., Oldebeken, S., et al. (2016). Mycobacterium tuberculosis induces the miR-33 locus to reprogram autophagy and host lipid metabolism. Nat. Immunol. 17 (6), 677-686. doi: 10.1038/ni.3434

Ouyang, Q., Zhang, K., Lin, D., Feng, C. G., Cai, Y., and Chen, X. (2020). Bazedoxifene Suppresses Intracellular Mycobacterium tuberculosis Growth by Enhancing Autophagy. mSphere 5 (2), e00124-20. doi: 10.1128/ mSphere.00124-20

Padhi, A., Pattnaik, K., Biswas, M., Jagadeb, M., Behera, A., and Sonawane, A. (2019). Mycobacterium tuberculosis LprE Suppresses TLR2-Dependent Cathelicidin and Autophagy Expression to Enhance Bacterial Survival in Macrophages. J. Immunol. 203 (10), 2665-2678. doi: 10.4049/ jimmunol.1801301

Pahari, S., Negi, S., Aqdas, M., Arnett, E., Schlesinger, L. S., and Agrewala, J. N. (2020). Induction of autophagy through CLEC4E in combination with TLR4: an innovative strategy to restrict the survival of Mycobacterium tuberculosis. Autophagy 16 (6), 1021-1043. doi: 10.1080/15548627.2019.1658436

Paik, S., Kim, J. K., Chung, C., and Jo, E. K. (2019). Autophagy: A new strategy for host-directed therapy of tuberculosis. Virulence 10 (1), 448-459. doi: 10.1080/ 21505594.2018.1536598

Painter, J. D., Galle-Treger, L., and Akbari, O. (2020). Role of Autophagy in Lung Inflammation. Front. Immunol. 11, 1337. doi: 10.3389/fimmu.2020.01337 
Palucci, I., and Delogu, G. (2018). Host Directed Therapies for Tuberculosis: Futures Strategies for an Ancient Disease. Chemotherapy 63 (3), 172-180. doi: $10.1159 / 000490478$

Park, K., Lee, S. E., Shin, K. O., and Uchida, Y. (2019). Insights into the role of endoplasmic reticulum stress in skin function and associated diseases. FEBS J. 286 (2), 413-425. doi: 10.1111/febs.14739

Pi, J., Shen, L., Yang, E., Shen, H., Huang, D., Wang, R., et al. (2020). MacrophageTargeted Isoniazid-Selenium Nanoparticles Promote Antimicrobial Immunity and Synergize Bactericidal Destruction of Tuberculosis Bacilli. Angew Chem. Int. Ed Engl. 59 (8), 3226-3234. doi: 10.1002/anie.201912122

Pilarski, A., Penn, N., Ratnakumar, S., Barker, R. D., and Milburn, H. J. (2016). Variation in vitamin $\mathrm{D}$ deficiency among tuberculosis patients by ethnic group and geographical region of birth: evidence from a diverse south London population. Eur. Respir. J. 48 (5), 1507-1510. doi: 10.1183/13993003.000572016

Puertollano, R., Ferguson, S. M., Brugarolas, J., and Ballabio, A. (2018). The complex relationship between TFEB transcription factor phosphorylation and subcellular localization. EMBO J. 37 (11), e98804. doi: 10.15252/ embj.201798804

Qian, M., Fang, X., and Wang, X. (2017). Autophagy and inflammation. Clin. Transl. Med. 6 (1), 24. doi: 10.1186/s40169-017-0154-5

Qian, J., Su, S., and Liu, P. (2020). Experimental Approaches in Delineating mTOR Signaling. Genes (Basel) 11 (7), 738. doi: 10.3390/genes11070738

Rabinowitz, J. D., and White, E. (2010). Autophagy and metabolism. Science 330 (6009), 1344-1348. doi: 10.1126/science.1193497

Rashid, H. O., Yadav, R. K., Kim, H. R., and Chae, H. J. (2015). ER stress: Autophagy induction, inhibition and selection. Autophagy 11 (11), 1956-1977. doi: 10.1080/15548627.2015.1091141

Rekha, R. S., Rao Muvva, S. S., Wan, M., Raqib, R., Bergman, P., Brighenti, S., et al. (2015). Phenylbutyrate induces LL-37-dependent autophagy and intracellular killing of Mycobacterium tuberculosis in human macrophages. Autophagy 11 (9), 1688-1699. doi: 10.1080/15548627.2015.1075110

Rekha, R. S., Mily, A., Sultana, T., Haq, A., Ahmed, S., Mostafa Kamal, S. M., et al. (2018). Immune responses in the treatment of drug-sensitive pulmonary tuberculosis with phenylbutyrate and vitamin D3 as host directed therapy. BMC Infect. Dis. 18 (1), 303. doi: 10.1186/s12879-018-3203-9

Roczniak-Ferguson, A., Petit, C. S., Froehlich, F., Qian, S., Ky, J., Angarola, B., et al. (2012). The transcription factor TFEB links mTORC1 signaling to transcriptional control of lysosome homeostasis. Sci. Signal 5 (228), ra42. doi: 10.1126/scisignal.2002790

Rogan, M. R., Patterson, L. L., Wang, J. Y., and McBride, J. W. (2019). Bacterial Manipulation of Wnt Signaling: A Host-Pathogen Tug-of-Wnt. Front. Immunol. 10, 2390. doi: 10.3389/fimmu.2019.02390

Romagnoli, A., Etna, M. P., Giacomini, E., Pardini, M., Remoli, M. E., Corazzari, M., et al. (2012). ESX-1 dependent impairment of autophagic flux by Mycobacterium tuberculosis in human dendritic cells. Autophagy 8 (9), 1357-1370. doi: 10.4161/auto.20881

Rouschop, K. M., van den Beucken, T., Dubois, L., Niessen, H., Bussink, J., Savelkouls, K., et al. (2010). The unfolded protein response protects human tumor cells during hypoxia through regulation of the autophagy genes MAP1LC3B and ATG5. J. Clin. Invest. 120 (1), 127-141. doi: 10.1172/JCI40027

Ruiz-Tagle, C., Naves, R., and Balcells, M. E. (2020). Unraveling the Role of MicroRNAs in Mycobacterium tuberculosis Infection and Disease: Advances and Pitfalls. Infect. Immun. 88 (3), e00649-19. doi: 10.1128/IAI.00649-19

Ryter, S. W., Cloonan, S. M., and Choi, A. M. (2013). Autophagy: a critical regulator of cellular metabolism and homeostasis. Mol. Cells 36 (1), 7-16. doi: $10.1007 / \mathrm{s} 10059-013-0140-8$

Sabir, N., Hussain, T., Shah, S. Z. A., Peramo, A., Zhao, D., and Zhou, X. (2018). miRNAs in Tuberculosis: New Avenues for Diagnosis and Host-Directed Therapy. Front. Microbiol. 9, 602. doi: 10.3389/fmicb.2018.00602

Sahu, S. K., Kumar, M., Chakraborty, S., Banerjee, S. K., Kumar, R., Gupta, P., et al. (2017). MicroRNA 26a (miR-26a)/KLF4 and CREB-C/EBPbeta regulate innate immune signaling, the polarization of macrophages and the trafficking of Mycobacterium tuberculosis to lysosomes during infection. PloS Pathog. 13 (5), e1006410. doi: 10.1371/journal.ppat.1006410

Sanjuan, M. A., Milasta, S., and Green, D. R. (2009). Toll-like receptor signaling in the lysosomal pathways. Immunol. Rev. 227 (1), 203-220. doi: 10.1111/j.1600065X.2008.00732.x
Schmeisser, K., and Parker, J. A. (2019). Pleiotropic Effects of mTOR and Autophagy During Development and Aging. Front. Cell Dev. Biol. 7, 192. doi: $10.3389 /$ fcell.2019.00192

Shi, L., Salamon, H., Eugenin, E. A., Pine, R., Cooper, A., and Gennaro, M. L. (2015). Infection with Mycobacterium tuberculosis induces the Warburg effect in mouse lungs. Sci. Rep. 5:18176. doi: 10.1038/srep18176

Shin, D. M., Jeon, B. Y., Lee, H. M., Jin, H. S., Yuk, J. M., Song, C. H., et al. (2010a). Mycobacterium tuberculosis eis regulates autophagy, inflammation, and cell death through redox-dependent signaling. PloS Pathog. 6 (12), e1001230. doi: 10.1371/journal.ppat.1001230

Shin, D. M., Yuk, J. M., Lee, H. M., Lee, S. H., Son, J. W., Harding, C. V., et al. (2010b). Mycobacterial lipoprotein activates autophagy via TLR2/1/CD14 and a functional vitamin D receptor signalling. Cell Microbiol. 12 (11), 1648-1665. doi: 10.1111/j.1462-5822.2010.01497.x

Silva, T., Moreira, A. C., Nazmi, K., Moniz, T., Vale, N., Rangel, M., et al. (2017). Lactoferricin Peptides Increase Macrophages' Capacity To Kill Mycobacterium avium. mSphere 2 (4), e00301-17. doi: 10.1128/mSphere.00301-17

Silva-Garcia, O., Valdez-Alarcon, J. J., and Baizabal-Aguirre, V. M. (2019). Wnt/ beta-Catenin Signaling as a Molecular Target by Pathogenic Bacteria. Front. Immunol. 10, 2135. doi: 10.3389/fimmu.2019.02135

Silwal, P., Kim, J. K., Yuk, J. M., and Jo, E. K. (2018). AMP-Activated Protein Kinase and Host Defense against Infection. Int. J. Mol. Sci. 19 (11), 3495. doi: 10.3390/ijms19113495

Silwal, P., Kim, Y. S., Basu, J., and Jo, E. K. (2020). The roles of microRNAs in regulation of autophagy during bacterial infection. Semin. Cell Dev. Biol. 101, 51-58. doi: 10.1016/j.semcdb.2019.07.011

Singh, P., and Subbian, S. (2018). Harnessing the mTOR Pathway for Tuberculosis Treatment. Front. Microbiol. 9, 70. doi: 10.3389/fmicb.2018.00070

Singh, N., Kansal, P., Ahmad, Z., Baid, N., Kushwaha, H., Khatri, N., et al. (2018). Antimycobacterial effect of IFNG (interferon gamma)-induced autophagy depends on HMOX1 (heme oxygenase 1)-mediated increase in intracellular calcium levels and modulation of PPP3/calcineurin-TFEB (transcription factor EB) axis. Autophagy 14 (6), 972-991. doi: 10.1080/15548627.2018.1436936

Sinigaglia, A., Peta, E., Riccetti, S., Venkateswaran, S., Manganelli, R., and Barzon, L. (2020). Tuberculosis-Associated MicroRNAs: From Pathogenesis to Disease Biomarkers. Cells 9 (10), 2160. doi: 10.3390/cells9102160

Sivangala Thandi, R., Radhakrishnan, R. K., Tripathi, D., Paidipally, P., Azad, A. K., Schlesinger, L. S., et al. (2020). Ornithine-A urea cycle metabolite enhances autophagy and controls Mycobacterium tuberculosis infection. Nat. Commun. 11 (1), 3535. doi: 10.1038/s41467-020-17310-5

Smulan, L. J., Martinez, N., Kiritsy, M. C., Kativhu, C., Cavallo, K., Sassetti, C. M., et al. (2021). Sirtuin 3 Downregulation in Mycobacterium tuberculosis-Infected Macrophages Reprograms Mitochondrial Metabolism and Promotes Cell Death. mBio 12 (1), e03140-20. doi: 10.1128/mBio.03140-20

Sprenkeler, E. G., Gresnigt, M. S., and van de Veerdonk, F. L. (2016). LC3associated phagocytosis: a crucial mechanism for antifungal host defence against Aspergillus fumigatus. Cell Microbiol. 18 (9), 1208-1216. doi: $10.1111 / \mathrm{cmi} .12616$

Stanley, S. A., Barczak, A. K., Silvis, M. R., Luo, S. S., Sogi, K., Vokes, M., et al. (2014). Identification of host-targeted small molecules that restrict intracellular Mycobacterium tuberculosis growth. PloS Pathog. 10 (2), e1003946. doi: 10.1371/journal.ppat.1003946

Sukhorukov, V. N., Khotina, V. A., Bagheri Ekta, M., Ivanova, E. A., Sobenin, I. A., and Orekhov, A. N. (2020). Endoplasmic Reticulum Stress in Macrophages: The Vicious Circle of Lipid Accumulation and Pro-Inflammatory Response. Biomedicines 8 (7), 210. doi: 10.3390/biomedicines 8070210

Talat, N., Perry, S., Parsonnet, J., Dawood, G., and Hussain, R. (2010). Vitamin d deficiency and tuberculosis progression. Emerg. Infect. Dis. 16 (5), 853-855. doi: 10.3201/eid1605.091693

Tameire, F., Verginadis, I. I., and Koumenis, C. (2015). Cell intrinsic and extrinsic activators of the unfolded protein response in cancer: Mechanisms and targets for therapy. Semin. Cancer Biol. 33, 3-15. doi: 10.1016/j.semcancer.2015.04.002

Tong, X., Ganta, R. R., and Liu, Z. (2020). AMP-activated protein kinase (AMPK) regulates autophagy, inflammation and immunity and contributes to osteoclast differentiation and functionabs. Biol. Cell 112 (9), 251-264. doi: 10.1111/ boc. 202000008

Villasenor, T., Madrid-Paulino, E., Maldonado-Bravo, R., Urban-Aragon, A., Perez-Martinez, L., and Pedraza-Alva, G. (2017). Activation of the Wnt 
Pathway by Mycobacterium tuberculosis: A Wnt-Wnt Situation. Front. Immunol. 8, 50. doi: 10.3389/fimmu.2017.00050

Wan, M., Tang, X., Rekha, R. S., Muvva, S., Brighenti, S., Agerberth, B., et al. (2018). Prostaglandin E2 suppresses hCAP18/LL-37 expression in human macrophages via EP2/EP4: implications for treatment of Mycobacterium tuberculosis infection. FASEB J. 32 (5), 2827-2840. doi: 10.1096/fj.201701308

Wang, H., Liu, Y., Wang, D., Xu, Y., Dong, R., Yang, Y., et al. (2019). The Upstream Pathway of mTOR-Mediated Autophagy in Liver Diseases. Cells 8 (12), 1597. doi: 10.3390/cells8121597

Watson, R. O., Manzanillo, P. S., and Cox, J. S. (2012). Extracellular M. tuberculosis DNA targets bacteria for autophagy by activating the host DNA-sensing pathway. Cell 150 (4), 803-815. doi: 10.1016/j.cell.2012.06.040

Watson, R. O., Bell, S. L., MacDuff, D. A., Kimmey, J. M., Diner, E. J., Olivas, J., et al. (2015). The Cytosolic Sensor cGAS Detects Mycobacterium tuberculosis DNA to Induce Type I Interferons and Activate Autophagy. Cell Host Microbe 17 (6), 811-819. doi: 10.1016/j.chom.2015.05.004

WHO (2020). World Health Organization Global tuberculosis Report 2020 (Geneva, 2020: World Health Organization).

Wu, X., Zhang, J., Ma, C., Li, W., Zeng, J., Wang, Y., et al. (2019). A role for Wnt/ beta-catenin signalling in suppressing Bacillus Calmette-Guerin-induced macrophage autophagy. Microb. Pathog. 127, 277-287. doi: 10.1016/ j.micpath.2018.12.016

Yan, M., Li, G., and An, J. (2017). Discovery of small molecule inhibitors of the Wnt/beta-catenin signaling pathway by targeting beta-catenin/Tcf4 interactions. Exp. Biol. Med. (Maywood) 242 (11), 1185-1197. doi: 10.1177/ 1535370217708198

Yang, T., and Ge, B. (2018). miRNAs in immune responses to Mycobacterium tuberculosis infection. Cancer Lett. 431, 22-30. doi: 10.1016/ j.canlet.2018.05.028

Yang, C. S., Song, C. H., Lee, J. S., Jung, S. B., Oh, J. H., Park, J., et al. (2006). Intracellular network of phosphatidylinositol 3-kinase, mammalian target of the rapamycin/70 $\mathrm{kDa}$ ribosomal $\mathrm{S} 6$ kinase 1 , and mitogen-activated protein kinases pathways for regulating mycobacteria-induced IL-23 expression in human macrophages. Cell Microbiol. 8 (7), 1158-1171. doi: 10.1111/j.14625822.2006.00699.x

Yang, C. S., Kim, J. J., Lee, H. M., Jin, H. S., Lee, S. H., Park, J. H., et al. (2014). The AMPK-PPARGC1A pathway is required for antimicrobial host defense through activation of autophagy. Autophagy 10 (5), 785-802. doi: 10.4161/ auto. 28072

Yang, R., Yang, E., Shen, L., Modlin, R. L., Shen, H., and Chen, Z. W. (2018). IL-12 +IL-18 Cosignaling in Human Macrophages and Lung Epithelial Cells Activates Cathelicidin and Autophagy, Inhibiting Intracellular Mycobacterial Growth. J. Immunol. 200 (7), 2405-2417. doi: 10.4049/jimmunol.1701073
Yao, S., Miao, C., Tian, H., Sang, H., Yang, N., Jiao, P., et al. (2014). Endoplasmic reticulum stress promotes macrophage-derived foam cell formation by upregulating cluster of differentiation 36 (CD36) expression. J. Biol. Chem. 289 (7), 4032-4042. doi: 10.1074/jbc.M113.524512

Yazbeck, V. Y., Buglio, D., Georgakis, G. V., Li, Y., Iwado, E., Romaguera, J. E., et al. (2008). Temsirolimus downregulates p21 without altering cyclin D1 expression and induces autophagy and synergizes with vorinostat in mantle cell lymphoma. Exp. Hematol. 36 (4), 443-450. doi: 10.1016/ j.exphem.2007.12.008

Yuan, Q., Chen, H., Yang, Y., Fu, Y., and Yi, Z. (2020). miR-18a promotes Mycobacterial survival in macrophages via inhibiting autophagy by downregulation of ATM. J. Cell Mol. Med. 24 (2), 2004-2012. doi: 10.1111/ jcmm.14899

Yuk, J. M., Shin, D. M., Lee, H. M., Yang, C. S., Jin, H. S., Kim, K. K., et al. (2009). Vitamin D3 induces autophagy in human monocytes/macrophages via cathelicidin. Cell Host Microbe 6 (3), 231-243. doi: 10.1016/j.chom.2009.08.004

Zhang, Q., Sun, J., Wang, Y., He, W., Wang, L., Zheng, Y., et al. (2017). Antimycobacterial and Anti-inflammatory Mechanisms of Baicalin via Induced Autophagy in Macrophages Infected with Mycobacterium tuberculosis. Front. Microbiol. 8, 2142. doi: 10.3389/fmicb.2017.02142

Zhao, T., Wu, K., Hogstrand, C., Xu, Y. H., Chen, G. H., Wei, C. C., et al. (2020). Lipophagy mediated carbohydrate-induced changes of lipid metabolism via oxidative stress, endoplasmic reticulum (ER) stress and ChREBP/PPARgamma pathways. Cell Mol. Life Sci. 77 (10), 1987-2003. doi: 10.1007/s00018-01903263-6

Zou, Z., Tao, T., Li, H., and Zhu, X. (2020). mTOR signaling pathway and mTOR inhibitors in cancer: progress and challenges. Cell Biosci. 10, 31. doi: 10.1186/ s13578-020-00396-1

Zumla, A., Maeurer, M.Host-Directed Therapies Network, C. (2015). HostDirected Therapies for Tackling Multi-Drug Resistant Tuberculosis: Learning From the Pasteur-Bechamp Debates. Clin. Infect. Dis. 61 (9), 1432 1438. doi: $10.1093 / \mathrm{cid} / \mathrm{civ} 631$

Conflict of Interest: The authors declare that the research was conducted in the absence of any commercial or financial relationships that could be construed as a potential conflict of interest.

Copyright $\odot 2021$ Silwal, Paik, Kim, Yoshimori and Jo. This is an open-access article distributed under the terms of the Creative Commons Attribution License (CC BY). The use, distribution or reproduction in other forums is permitted, provided the original author(s) and the copyright owner(s) are credited and that the original publication in this journal is cited, in accordance with accepted academic practice. No use, distribution or reproduction is permitted which does not comply with these terms. 